\title{
THERMAL-FLOW CODE FOR MODELING GAS DYNAMICS AND HEAT TRANSFER IN SPACE SHUTTLE SOLID ROCKET MOTOR JOINTS
}

\author{
Qunzhen Wang*, Edward C. Mathias', Joe R. Heman' and Cory W. Smith' \\ Thiokol Propulsion, Cordant Technologies Inc. \\ P.O. Box 707, M/S 252, Brigham City, UT 84302
}

\section{INTRODUCTION}

It is important to accurately predict the pressure, temperature, as well as the amount of O-ring erosion in the space shuttle Reusable Solid Rocket Motor (RSRM) joints in the event of a leak path. The scenarios considered are typically hot combustion gas rapid pressurization events of small volumes through narrow, restricted flow paths. The ideal method for this prediction is a transient three-dimensional computational fluid dynamics calculation with computational domain including both the combustion gas and the surrounding solid regions. However, this has not yet been demonstrated to be economical for this application due to the enormous amount of computer time and memory required. Consequently, all CFD applications in RSRM joints ${ }^{1,2}$ are steady-state simulations with solid regions being excluded from the computational domain by either assuming a constant wall temperature or assuming no heat transfer between the hot combustion gas and cool solid walls.

Currently there are two computer codes, known to the authors, available to model the gas dynamics, heat transter, and O-ring erosion in the RSRM joint pressurization process. One is ORING2 $2^{3-6}$, which was developed at Thiokol Propulsion, and the other is JPR? which was developed at NASA Marshall Space Flight Center. A way to improve the current prediction technique is to modify the transient compressible flow calculation since the pressure, temperature, and velocity of the combustion gas are not calculated from the time-dependent Navier-Stokes equations. Instead. some empirical correlations are used to predict the gas temperature, mass flow rate, and other flow properties by assuming a quasi-steady state flow in a constant cross-section area pipe (i.e., there is no grid in the paths). Furthermore, ORING2 can only handle configurations with two volumes and two paths while it takes significant coding for JPR to do complicated configurations with more than two volumes.
A new thermal-flow simulation code, called SFLOW, has been developed to model the gas dynamics, heat transfer, as well as O-ring and flow path erosion inside the space shuttle RSRM joints. The details are discussed in this paper. The SFLOW methodology eliminates some of the approximations inherent in other simulation and prediction tools. This is accomplished by combining SINDA/G ${ }^{\text {(Network Analysis, Inc. }}{ }^{8}$ ), a commercial thermal analyzer, and SHARP ${ }^{\text {89.14, a }}$ general-purpose CFD code developed at Thiokol Propulsion. The pressure, temperature, and velocity of the combustion gas in the leak paths are calculated in SHARP" by solving the time-dependent Navier-Stokes equations while the heat conduction in the solid is modeled by SINDA $/ G^{\$}$. The two codes are coupled by the heat transfer at the solid-gas interface. The number of flow paths and volumes in SFLOW is limited only by the memory of the computer used to run SFLOW.

Although SHARP ${ }^{\$}$ can solve one-dimensional, twodimensional, as well as three-dimensional flow problems, the flow inside paths is assumed to be onedimensional in the current version of SFLOW to reduce the CPU time and memory requirements. This is a reasonable approximation due to the fact that leak paths are usually narrow. The solid in SFLOW, however, can be one-dimensional, two-dimensional, as well as threedimensional since it is not always a good approximation to assume the heat conduction in the solid region is one-dimensional, especially when the wall material is metal. This is feasible in terms of CPU time and memory because there is only one equation (i.e., conservation of energy) to solve in the solid region compared to five equations (i.e., conservation of mass, momentum, and energy) needed in the gas region if the flow is modeled as three-dimensional. Furthermore, a larger time step can be used in the solid calculation than that used in the gas calculation since the solid temperature usually changes much slower than the flow properties.

Copyright $\odot 2000$, Thiokol Propulsion, a Division of Cordant Technolgies Inc.

Published by the American Institute of Aeronautics and Astronautics, Inc., with permission.

-Principal Engineer, Gas Dynamics, AIAA member

- Principal Engineer, Heat Transfer, AIAA member

Senior Engineeer, Heat Transfer 
The SHARP ${ }^{\infty}$ main program is converted into a subroutine so that it can be called from SINDA/G ${ }^{\mathrm{a}}$. The input for this subroutine includes the heat flux from gas to wall, friction factor of the flow path, mass addition due to erosion, gas properties, grid, as well as boundary and initial conditions while the output is the pressure, temperature, and velocity of the gas for each tlow cell at a specific time step. In SFLOW, the flow calculation (i.e., SHARP ${ }^{\text {Io }}$ ) and the solid calculation (i.e., SINDA $/ G^{\otimes}$ ) are decoupled from each other such that a smaller time step can be applied in SHARP $^{\text {tion }}$ than that used in SINDA $/ G^{\infty}$. Furthermore, SHARP ${ }^{\star}$ can use more cells for the flow solution than the number passed from SINDA $/ G^{\boxplus}$ solid surfaces.

As a general-purpose CFD code, SHARP ${ }^{\bowtie}$ does not have the friction term in the governing equations since it is typically used for two-dimensional and threedimensional flow simulations where the friction is implicitly taken into account by the viscous force in the resolved near-wall region or by a wall function. In onedimensional flows, however, the friction term has to be explicitly added due to the fact that the velocity gradient in the wall-normal direction does not exist. Similarly, a heat transfer term is added to the SHARP equations because the thermal boundary layer is not simulated in SFLOW. Moreover, a mass addition term is added in SHARP ${ }^{\$}$ since the erosion of the wall material will generate mass. Finally, minor loss terms such as those due to sudden expansion or contraction and flow direction change are accounted for by specifying a loss coefficient in the SFLOW input file at the appropriate flow cells.

The details of the solution scheme, including the modeling of gas dynamics, heat transfer, as well as Oring and path erosion, are discussed in the next section, followed by comparison of SFLOW predictions to exact solutions or experimental data. The test cases included Fanno flow where friction is important, Rayleigh flow where heat transfer between gas and solid is important, flow with mass addition due to the erosion of the solid wall, transient volume venting process, as well as some transient one-dimensional flows with analytical solutions derived by $\mathrm{Cai}^{15}$. In addition, SFLOW has been applied to model the RSRM nozzle joint 4 subscale hot-flow tests ${ }^{16}$. which simulate flows to the primary and secondary O-rings. The predicted pressure, temperature (both gas and solid), and O-ring erosion from SFLOW are compared with the measured data in this paper.

\section{GAS DYNAMICS AND THERMAL MODELING}

\section{GAS DYNAMICS MODELING}

In SFLOW, the gas can be either in a flow path or a volume (i.e., cavity), which are treated very differently. The gas in a volume is assumed to be in quasiequilibrium with uniform pressure, temperature, and no velocity whereas that in a path is solved from the first principles (i.e., conservation of mass, momentum and energy).

\section{Gas flow in paths}

The transient compressible flow in a path is modeled using SHARP ${ }^{\$}$, which is a general-purpose CFD code. SHARP ${ }^{\otimes}$ solves the Reynolds averaged Navier-Stokes equations in one-dimensional form as

$$
\frac{\partial Q}{\partial t}+\frac{\partial\left(E_{i}-E_{i}\right)}{\partial x}=S
$$

where the unknowns are

$$
Q=A\left[\begin{array}{c}
\rho \\
\rho u \\
e
\end{array}\right]
$$

In equation (2), $A$ is the cross-section area, which is a function of both space $x$ and time $t$, and $\rho$ and $u$ are the Reynolds averaged density and velocity, respectively. The total energy is

$$
e=\rho\left(c_{v} T+\frac{1}{2} u^{2}\right)
$$

where $T$ is the Reynolds averaged temperature and $c_{v}$ is the specific heat at constant volume. The inviscid flux term is given by

$$
E_{i}=A\left[\begin{array}{c}
\rho u \\
\rho u^{2}+p \\
(e+p) u
\end{array}\right]
$$

while the viscous term is

$$
E_{v}=A\left[\begin{array}{c}
0 \\
\tau_{11} \\
u \tau_{11}+q_{1}
\end{array}\right]
$$


The total stress and heat flux include both laminar parts and turbulence parts as

$$
\begin{gathered}
\tau_{11}=\frac{2}{3}\left(\mu^{L}+\mu^{T}\right) \frac{\partial u}{\partial x} \\
q_{1}=-\left(\frac{\mu^{L}}{(\gamma-1) \operatorname{Pr}^{L}}+\frac{\mu^{T}}{(\gamma-1) \operatorname{Pr}^{T}}\right) \frac{\partial T}{\partial x}
\end{gathered}
$$

where $\mu^{\prime}$ and $\operatorname{Pr}^{t}$ are the laminar viscosity and Prandtl number while $\operatorname{Pr}^{r}$ is the turbulent Prandtl number. The turbulent viscosity $\mu^{r}$ is zero for laminar flow while it is obtained by the widely used $k-\varepsilon$ model for turbulent flow. The source term in equation (1) is

$$
S=\left[\begin{array}{c}
\dot{m} \\
-\frac{\pi}{8} f D_{h} \rho u^{2}-\frac{1}{2} \frac{\partial\left(K A \rho u^{2}\right)}{\partial x} \\
-\dot{q}-\frac{\pi}{8} f D_{h} \rho|u|+-\frac{1}{2} \frac{\partial\left(K A \rho u^{3}\right)}{\partial x}
\end{array}\right]
$$

where $\dot{m}$ is the mass addition rate due to path erosion, $f$ is the Darcy friction factor, $D_{h}$ is the hydraulic diameter of the path, $K$ is the minor loss coefficient and $\dot{q}$ is the heat transfer rate per unit volume from the gas to the solid wall. The boundary conditions for the path flowfield are obtained from the pressure and temperature of the volumes. A path has to be connected with a volume at one end; the other end can be connected to a volume or a solid wall, which could be either adiabatic or conducting heat away to the solid region.

Note that, similar to other general-purpose CFD codes, SHARP $^{(1)}$ does not have the friction term shown in equation (8) since it is typically used for $2 D$ and $3 D$ flow simulations where the friction is implicitly taken into account by the viscous force in the resolved nearwall region or by the wall function applied. In onedimensional flows, however, the friction term has to be explicitly accounted for due to the fact that the velocity gradient $\partial u / \partial y$ does not exist. Similarly, the heat transfer term in equation (8) is added to SHARP ${ }^{\$}$ due to the fact that the thermal boundary layer is not simulated in SFLOW. The mass addition terms are also added since the erosion or decomposition of the walls will generate this effect. Finally, minor loss terms such as those due to sudden expansion or contraction and turns or bends in the flow path are added in equation (8).

\section{Friction factor in the flow paths}

The friction factor in equation (8) is obtained from the empirical correlation of Idelchik ${ }^{17}$, which depends on both the shape of the path (i.e., circular, rectangular, or triangular) and whether the flow is laminar, turbulent, or in transition.

According to Idelchik ${ }^{17}$, the gas flow is divided into laminar, turbulent, and transitional regimes depending on the cutoff Reynolds numbers defined as

$$
\begin{gathered}
\operatorname{Re}_{a}=754 \exp \left(0.0065 D_{h} / \varepsilon\right) \\
\operatorname{Re}_{b}=1160 \exp \left(\frac{D_{h}}{\varepsilon}\right)^{(1.11} \\
\operatorname{Re}_{c}=20900 \exp \left(\frac{D_{h}}{\varepsilon}\right)^{0.10635}
\end{gathered}
$$

where $\varepsilon$ is the roughness of the flow path. The flow is laminar if the Reynolds number is below $\operatorname{Re}_{\mathrm{a}}$, turbulent if the Reynolds number is above $\mathrm{Re}_{c}$, and in the transitional regime if the Reynolds number is between $\mathrm{Re}_{\mathrm{a}}$ and $\mathrm{Re}_{\mathrm{c}}$. If there are two transitional zones, $\mathrm{Re}_{\mathrm{b}}$ is used to determine which of the two zones the flow is in.

The friction factor in the flow path is then determined based on the flow Reynolds number as:

- for $\operatorname{Re}<\mathrm{Re}_{\text {" }}$

$$
f=\frac{64}{\mathrm{Re}}
$$

- for $\operatorname{Re}_{\text {, }} \leq \operatorname{Re}<\operatorname{Re}_{b}$

$$
f=4.4 \operatorname{Re}^{-10.545} \exp \left(\frac{-0.00275 \varepsilon}{D_{h}}\right)
$$

- for $\operatorname{Re}_{b} \leq \operatorname{Re}<\operatorname{Re}_{c}$

$$
\begin{gathered}
f=\left(0.1+5\left(\frac{\varepsilon}{D_{l t}}\right)^{1134}-V a l\right) \exp \left(-0.0017^{2}(\operatorname{Re}-\mathrm{Re})^{2}\right)+V a l \\
V a l=0.758-0.0109\left(\frac{\varepsilon}{D_{h}}\right)^{-10.2 \times a}
\end{gathered}
$$

- for $\operatorname{Re} \geq \operatorname{Re}_{c}$

$$
f^{-2}=-2 \log \left(\frac{\varepsilon}{3.7 D_{t}}+\frac{2.51}{\operatorname{Re} \sqrt{f}}\right)
$$

- for $\mathrm{Re}_{a} \leq \mathrm{Re}<\mathrm{Re}_{\text {c }}$ and $\mathrm{Re}_{b} \leq \mathrm{Re}_{a}$ there is only one transitional zone 


$$
\begin{aligned}
& f=\left(7.244 \operatorname{Re}^{-0.043}-0.32\right) \exp \\
& \left(-0.0017^{2}\left(\operatorname{Re}_{c}-\operatorname{Re}\right)^{2}\right)+0.032
\end{aligned}
$$

\section{Pressure and temperature in volumes}

Once the flowfield in the path is solved by SHARP ${ }^{\infty}$, the pressure and temperature in the volumes can be obtained from mass conservation

$$
\frac{\partial}{\partial t}(m)=\dot{m}_{r}+\sum \dot{m}
$$

and energy conservation

$$
\frac{\partial}{\partial t}\left(m c_{v} T\right)=\sum \dot{m} h-\dot{Q}
$$

where the summation is for all paths which connect to this volume, $\dot{m}$ and $h$ are the mass flow rate and enthalpy at the end of the path, $\dot{m}_{e}$ is the rate of mass addition to the gas due to surface erosion, $\dot{Q}$ is the heat transfer rate from the gas to the solid boundary which includes the convective heat transter as well as the heat transfer due to erosion, $m, P$, and $T$ are the mass, pressure and temperature of the gas in this volume, respectively. In addition to equations (18) and (19), the ideal gas law

$$
p V=m R T
$$

where $V$ is the volume of the cavity, was used to solve the pressure $p$, temperature $T$, and mass $m$ of the volume.

\section{HEAT TRANSFER MODELING}

The convective heat transfer between the gas and the solid wall is modeled as

$$
\dot{q}=h A_{s}\left(T_{s}-T_{w}\right)
$$

where $h$ is the heat transfer coefficient, $A_{s}$ is the surface area, $T_{g}$ and $T_{w}$ are the temperature of the gas and solid wall, respectively. This heat transfer rate is used in both SHARP ${ }^{\$}$ and SINDA/G ${ }^{\circledast 6}$ so that the total energy in the system is conserved.

\section{Heat transfer in paths}

The heat transfer coefficient in flow paths can be obtained from the Nusselt number as

$$
h=N_{u} \frac{k}{D}
$$

where $k$ is the thermal conductivity. The Nusselt number depends on both the cross-section shape of the path and the flow regime. If the flow is laminar and the path is circular

$$
N_{u}=4.36
$$

while for rectangular paths

$$
N_{u}=1.18135+2.30595 r^{10.113245}
$$

where

$$
r=\min \left[16, \frac{\max (a, b)}{\min (a, b)}\right]
$$

with $a$ and $b$ being the width and height. For turbulent flow, the Nusselt number is calculated using the following empirical correlation

$$
N_{u}=\frac{f \operatorname{Pr} \operatorname{Re}}{\max \left(\operatorname{Pr}^{2 / 3},\left(1.07-12.7 \sqrt{f / 8}\left(\operatorname{Pr}^{2 / 1}-1\right)\right)\right.}\left(\frac{\mu_{s}}{\mu_{w}}\right)^{0.14}
$$

where $f$ is the friction factor calculated from equation (12) through (17), and $\mu_{B}$ and $\mu_{w}$ are the viscosity evaluated at the average gas temperature and wall temperature, respectively. In the transitional regime, a linear interpolation between the laminar and turbulent Nusselt number is applied.

\section{Jet impingement heat transfer}

The jet impingement heat transfer correlation used in SFLOW is the same as that in ORING2 and JPR, which depends on the standoff distance to diameter ratio as well as whether the flow is laminar, turbulent, or in the transitional regime. The heat transfer coefficient is obtained from the Stanton number as

$$
h=S_{1} c_{n} \frac{\dot{m}}{A}
$$

If the flow is laminar, the Stanton number is

$$
S_{t}=0.763 \operatorname{Pr}^{-11.6} \sqrt{\frac{1}{\operatorname{Re}}}\left(\frac{T_{g}}{T_{w}}\right)^{1 / 6}
$$

where the Reynolds number $\mathrm{Re}$ is calculated at the jet exit, $T_{g}$ is the gas temperature at the jet exit, and $T_{w}$ is the temperature of the wall surface. For turbulent flow with a stand off distance to jet diameter ratio $L / D \leq 2.6$

$$
S_{1}=0.763 \operatorname{Pr}^{-1.1 .6} \sqrt{\frac{V_{\text {grut }}}{\operatorname{Re}}}\left(\frac{T_{8}}{T_{w}}\right)^{1 / 6}
$$

while for $L / D>2.6$ 


$$
S_{t}=0.442 \operatorname{Pr}^{-116}\left(1+\frac{L e^{0.52}-1}{2}\right) \sqrt{\frac{2 L V_{z r u d}}{D R e}}\left(\frac{T_{k}}{T_{w}}\right)^{1 / 3}
$$

where $L e$ is the Lewis number. The velocity gradient in the above equations is

$$
V_{\text {groud }}=1
$$

for $L / D<3.4$,

$$
v_{\text {vruad }}=1-0.196\left(\frac{L / D-3.4}{5}\right)^{2}
$$

for $3.4 \leq L / D<8.4$, and

$$
V_{\text {zrod }}=\frac{1-\exp \left(\frac{-1}{0.2315 L / D-0.74}\right)}{0.13 L / D-0.39}
$$

for $L / D \geq 8.4$. If the flow is in transitional regime, the heat transfer coefficient is obtained by linear interpolation between laminar and turbulent regimes.

\section{Heat rransfer in volumes}

The heat transfer from the gas in a volume to the solid boundary can be modeled in four different ways

- Using the impingement jet heat transfer correlation described above

- Using the heat transfer coefficient in the paths connected to this volume

- Using a conduction length as $h=k / l$

- Using a user-specified heat transfer coefficient

The user of SFLOW specifies which of these methods should be applied to calculate heat transfer coefficient for all the gas-solid interfaces in all volumes.

\section{EROSION MODELING}

The erosion model used in SFLOW is the same as that in ORING2 and JPR. Specifically, the erosion rate is a function of heat transfer coefficient between gas and solid. the gas temperature, as well as the wall temperature. Erosion has the following effects on the gas:

- Increases the cross-section area of the path or the volume of the cavity

- Adds mass to the gas

- Adds energy to the gas

\section{VALIDATION CASES}

For all the validation cases shown in this section, there are only two volumes connected by one flow path. The pressure and temperature in one or both volumes are specified as input whereas the pressure, temperature, and velocity in the flow path are calculated using SFLOW. Most of these tests are for SHARP ${ }^{\$}$ in solving one-dimensional tlow problems with friction, heat transfer, mass addition. and area change since no modification is made to the commercial thermal code SINDA $/ G^{k}$.

\section{FANNO FLOW}

For air entering an adiabatic 100 -ft-diameter duct with a total pressure of $3183.65 \mathrm{lbf} / \mathrm{ft}^{2}$ and total temperature of $540^{\circ} \mathrm{R}$, it can be shown analytically that the inlet and outlet Mach number will be 0.8 and 0.9 , respectively, if the friction coefficient is assumed to be 0.0578 , the pipe length is $100 \mathrm{ft}$, and the outlet pressure is 1829.12 $\mathrm{lbf} / \mathrm{ft}^{2}$. SFLOW was used to simulate this test case and the results are compared with the analytical solutions in Table 1. It is clear that the error in the predicted Mach number is smaller when more tlow cells are applied. However, the error drops much more from 20 cells to 200 cells than that from 200 cells to 1,000 cells. For this particular case, 200 cells are enough to keep the error in both inlet and outlet Mach number below $0.55 \%$.

Table 1. The Mach Number Predicted by SFLOW for the Fanno Flow Test Case

\begin{tabular}{|l|c|c|c|}
\hline & 20 cells & 200 cells & 1,000 cells \\
\hline$M_{m}$ & 0.8232 & 0.8043 & 0.8027 \\
\hline error in $M_{m}$ & $2.90 \%$ & $0.54 \%$ & $0.34 \%$ \\
\hline$M_{\text {rut }}$ & 0.8900 & 0.8954 & 0.8958 \\
\hline error in $M_{\text {sut }}$ & $1.11 \%$ & $0.51 \%$ & $0.47 \%$ \\
\hline
\end{tabular}

\section{RAYLEIGH FLOW}

For air entering a frictionless $0.1-\mathrm{ft}$-diameter, $100-\mathrm{ft}$ long duct with a total pressure of $1481 \mathrm{lbf} / \mathrm{ft}^{2}$ and total temperature of $524^{\circ} \mathrm{R}$, it can be shown analytically that the inlet and outlet Mach number will be 0.2 and 0.25 , respectively, if the heat addition is assumed to be $60.367 \mathrm{BTU} / \mathrm{lbm}$, and the outlet pressure is $1389 \mathrm{lbf} / \mathrm{ft}^{2}$. SFLOW was used to simulate this test case and the results are shown in Table 2. The error in the predicted inlet Mach number drops more from 20 cells to 200 cells than from 200 cells to 1,000 cells. For the outlet 
Mach number, the error actually increases from 20 cells to 200 cells, but decreases slightly from 200 cells to 1,000 cells. For this particular case, 200 cells are enough to keep the error in both inlet and outlet Mach number below $0.65 \%$.

Table 2. The Mach Number Predicted by SFLOW for the Rayleigh Flow Test Case

\begin{tabular}{|l|c|c|c|}
\hline & 20 cells & 200 cells & 1,000 cells \\
\hline$M_{\prime \prime \prime}$ & 0.1954 & 0.1987 & 0.1991 \\
\hline error in $M_{\text {in }}$ & $2.30 \%$ & $0.65 \%$ & $0.45 \%$ \\
\hline$M_{\text {rut }}$ & 0.2498 & 0.2484 & 0.2485 \\
\hline error in $M_{\text {ous }}$ & $0.08 \%$ & $0.64 \%$ & $0.60 \%$ \\
\hline
\end{tabular}

\section{MASS ADDITION}

For air entering a frictionless adiabatic 0.1 -ft-diameter duct with a total pressure of $1708 \mathrm{lbf} / \mathrm{ft}^{2}$ and total temperature of $525^{\circ} \mathrm{R}$, it can be shown analytically that the inlet and outlet Mach number will be 0.5 and 0.6 , respectively, if $0.021 \mathrm{lbm} / \mathrm{sec}$ of air at a temperature of $525^{\circ} \mathrm{R}$ is added to the flow and the outlet pressure is $1421 \mathrm{lbf} / \mathrm{ft}^{2}$. SFLOW was used to simulate this test case and the results are shown in Table 3. With 200 or more flow cells, the error in the inlet Mach number is less than $1.4 \%$ while that in the outlet Mach number is less than $0.35 \%$.

Table 3. The Mach Number Predicted by SFLOW for the Mass Addition Test Case

\begin{tabular}{|l|c|c|c|}
\hline & 20 cells & 200 cells & 1.000 cells \\
\hline$M_{m}$ & 0.5088 & 0.5068 & 0.5069 \\
\hline crror in $M_{m}$ & $1.76 \%$ & $1.36 \%$ & $1.38 \%$ \\
\hline$M_{\text {sut }}$ & 0.5917 & 0.5979 & 0.5984 \\
\hline error in $M_{\text {uur }}$ & $1.38 \%$ & $0.35 \%$ & $0.27 \%$ \\
\hline
\end{tabular}

\section{TRANSIENT FLOW WITH AREA CHANGE}

All the test cases shown above are steady state problems so only the SFLOW predictions at long times were compared with the exact steady state solution. In this and the following three sections, SFLOW was tested using one-dimensional unsteady flow cases with analytical solutions derived by $\mathrm{Cai}^{16}$.

It can be shown that for one-dimensional compressible flow in a circular pipe with a cross-section area

$$
A=\frac{C_{3}}{C_{0} x+C_{2}}
$$

the exact solution of the governing equation is

$$
\begin{gathered}
\rho=\text { const } \\
\rho=\text { const } \\
u=\frac{2 C_{10}\left(C_{01} x+C_{2}\right)}{2 C_{11}^{2} t+C_{1}}
\end{gathered}
$$

if both friction and heat transfer are neglected. This transient flow with area change case is simulated using SFLOW with a uniform grid of 20 flow cells by assuming $C_{0}=C_{1}=C_{3}=1$ and $C_{2}=100$. The flow path is from $x=0$ to $x=20 \mathrm{~m}$ and the time is from $t=0 \mathrm{sec}$ to $t=1 \mathrm{sec}$. The velocity at the inlet and outlet from SFLOW are compared with the exact solution in Figure 1, which shows a very good agreement even though only 20 flow cells are used.

Transient Flow With Area Change

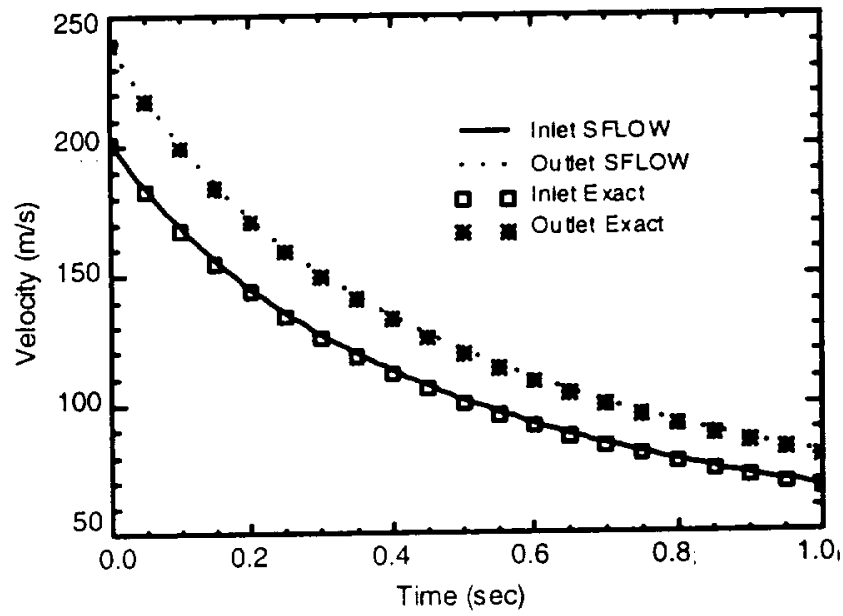

Figure 1. Comparison of the Predicted Velocity From SF LOW With the Analytical Solution of Equation (35)

\section{TRANSIENT FLOW WITH HEAT TRANSFER}

It can be shown that for one-dimensional compressible flow in a circular pipe with a heat transfer rate per unit mass of

$$
q=\frac{\gamma}{\gamma-1} \frac{C_{1} p}{C_{5}}\left(\frac{C_{1} x+C_{1}}{C_{1} t+C_{2}}\right)^{1+C_{1} / C_{1}}
$$

the exact solution of the governing equation is

$$
\begin{gathered}
p=\text { const } \\
\rho=\frac{C_{5}\left(C_{1} t+C_{2}\right)^{c_{1} / C_{1}}}{\left(C_{1} x+C_{1}\right)^{1+C_{1} / C_{1}}} \\
u=\frac{C_{1} x+C_{3}}{C_{1} t+C_{2}}
\end{gathered}
$$


if the cross-section area is constant and the friction is neglected. This transient flow with heat transfer case was simulated using SFLOW with a uniform grid of 200 flow cells by assuming $C_{1}=C_{4}=1$. $C_{3}=C_{5}=5000$ and $C_{2}=15$. The flow path is from $x=0$ to $x=20 \mathrm{~m}$ and the time is from $t=0 \mathrm{sec}$ to $t=1 \mathrm{sec}$. The velocity and temperature at the inlet and outlet from SFLOW are compared with the exact solution in Figure 2 and Figure 3. The velocity profile at both the inlet and outlet agree very well with the analytical solution and the agreement for the temperature is also reasonable. Although not shown here, the results using 20 cells are much worse than those shown in Figure 2 and Figure 3 and it is expected

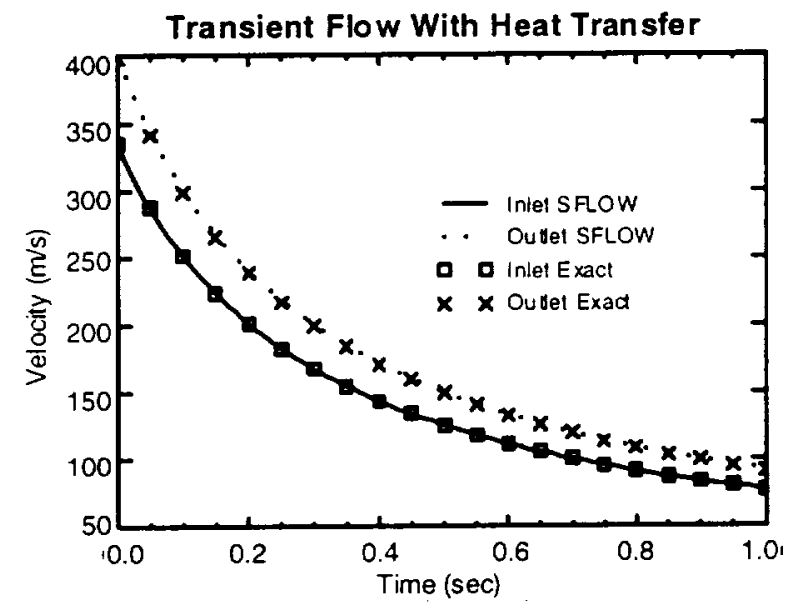

Figure 2. Comparison of the Predicted Velocity From SFLOW With the Analytical Solution of Equation (37)

Transient Flow With Heat Transfer

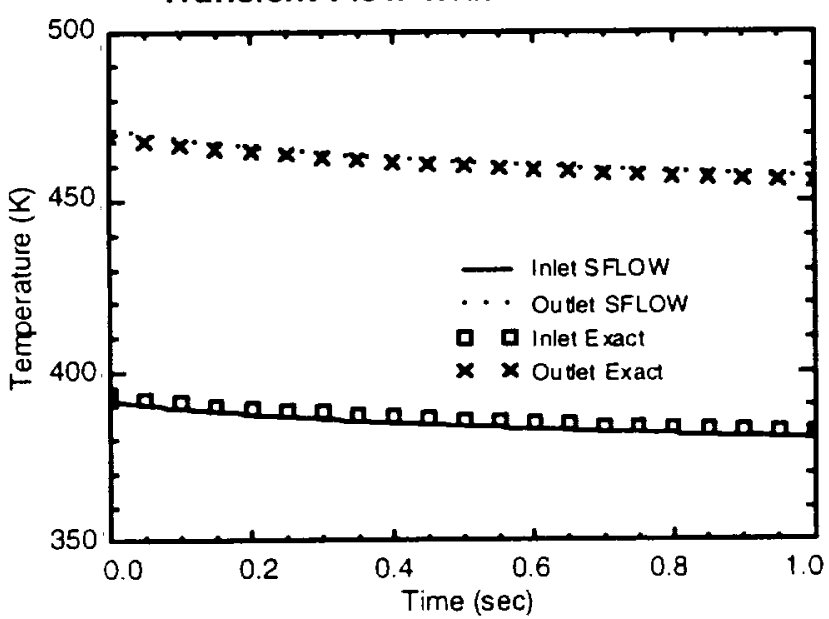

Figure 3. Comparison of the Predicted Temperature From SFLOW With the Analytical Solution of Equation (37) that a better temperature prediction would be obtained by using even more flow cells.

\section{TRANSIENT FLOW WITH FRICTION AND HEAT TRANSFER}

It can be shown that for one-dimensional compressible flow in a circular pipe with a heat transfer rate per unit mass of fluid

$$
q=-\frac{16 A}{\pi f^{2} t^{3}}
$$

the exact solution of the governing equation is

$$
\begin{aligned}
& p=\text { const } \\
& \rho=\text { const } \\
& u=\frac{4 \sqrt{A}}{\sqrt{\pi} f t}
\end{aligned}
$$

if both the cross-section area and friction factor are constant. This transient flow with heat transfer and constant friction factor case was simulated using SFLOW with a uniform grid of 20 flow cells and $f=0.004 / \sqrt{\pi}$. The flow path is from $x=0$ to $x=20 \mathrm{~m}$ and the time is from $t=5 \mathrm{sec}$ to $t=10 \mathrm{sec}$. The velocity at the inlet and outlet, which are the same at any given time according to equation (39), , from SFLOW are compared with the exact solution in Figure 4 , which shows a very good agreement even though only 20 tlow cells are used.

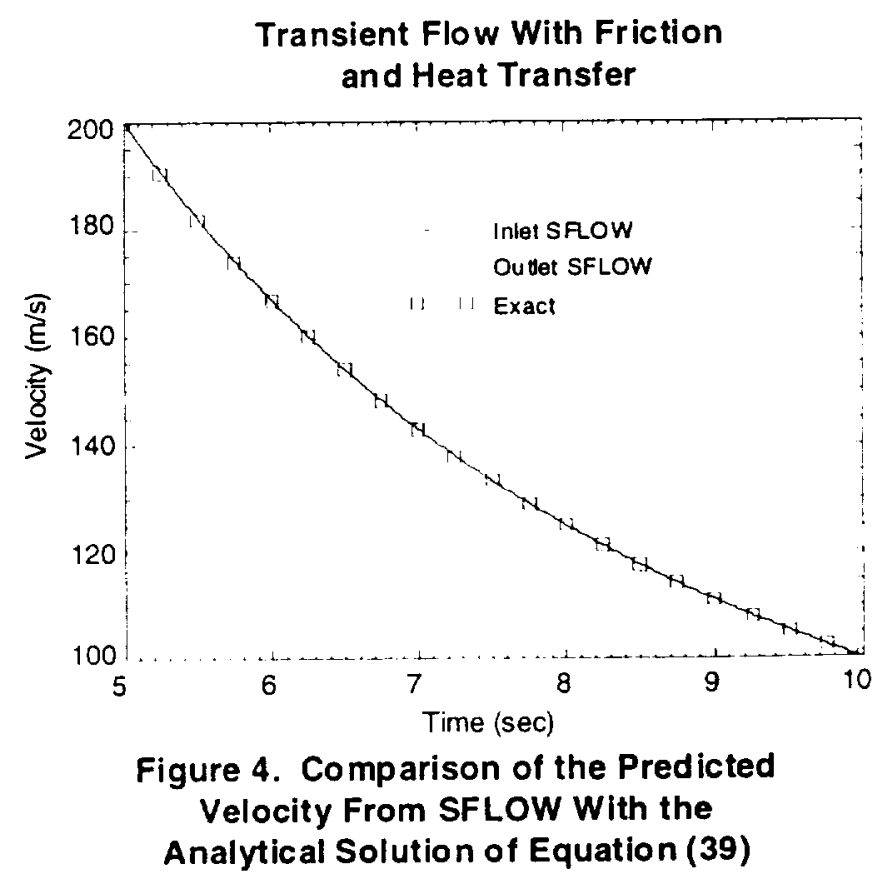




\section{TRANSIENT FLOW WITH AREA CHANGE,}

\section{FRICTION AND HEAT TRANSFER}

It can be shown that for one-dimensional compressible flow in a circular pipe with area $A$, friction factor $f$, and heat transfer rate $q$ given by

$$
\begin{gathered}
A=\frac{1}{C_{4} \exp \left(-\sqrt{\pi / C_{1}} x\right)+\sqrt{C_{x} / \pi}} \\
f=\frac{4}{\sqrt{C_{1}\left(C_{4} \exp \left(-\sqrt{\pi / C_{1}} x\right)+\sqrt{C_{1} / \pi}\right)}} \\
y=-\sqrt{\frac{\pi}{C_{1}}\left(\frac{C_{2}\left(C_{4} \exp \left(-\sqrt{\pi / C_{1}} x\right)+\sqrt{C_{1} / \pi}\right)}{C_{2} t+C_{1}}\right)}
\end{gathered}
$$

the exact solution of the governing equation is

$$
\begin{gathered}
p=\text { const } \\
\rho=\text { const } \\
u=\frac{C_{2}\left(C_{4} \exp \left(-\sqrt{\pi / C_{1} x}\right)+\sqrt{C_{.} / \pi}\right)}{C_{2} t+C_{3}}
\end{gathered}
$$

This transient flow with area change, friction, and heat transfer case is simulated using SFLOW with a uniform grid of 20 flow cells by assuming $C_{10}=C_{3}=C_{4}=1$, $C_{1}=1000$ and $C_{2}=15$. The flow path is from $x=0$ to $x=20 \mathrm{~m}$ and the time is from $t=0 \mathrm{sec}$ to $t=0.1 \mathrm{sec}$. The velocity at the inlet and outlet from SFLOW are compared with the exact solution in Figure 5 , which shows a very good agreement even though only 20 flow cells are used.

\section{Transient Flow With Area Change, Friction and Heat Transfer}

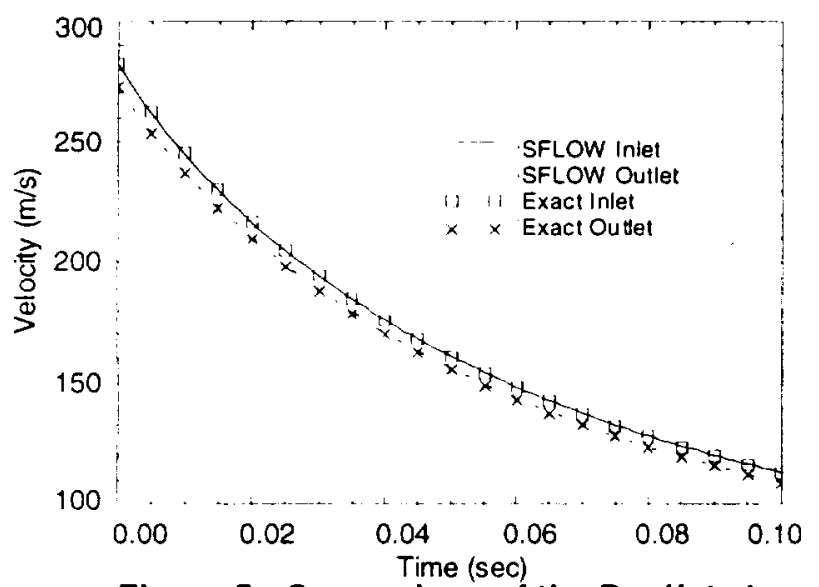

Figure 5. Comparison of the Predicted Velocity From SFLOW With the Analytical Solution of Equation (43)

\section{VOLUME VENTING}

The cases discussed above focus on the gas flow in paths since only pressure, temperature, and velocity of the gas in the pipe were compared with the analytical solutions. To validate the volume pressure and temperature algorithm, the SFLOW prediction in a volume-venting experiment is compared with the measured data. In the experiment, a tank with a volume of $62.024 \mathrm{in}^{3}$ is connected to a 2.27 in circular pipe with a diameter of $0.072 \mathrm{in}$, which is open to ambient conditions at 12.5 psia. The tank is at ambient condition initially and the tank pressure is increased to about 258 psia from $t=-10 \mathrm{sec}$ to $t=0$ with the valve between the tank and pipe closed. This valve is opened at $t=0$ and the tank pressure begins to fall. The SFLOW prediction starts from $t=0$ using 20 flow cells in the pipe. The comparison of the predicted pressure with the experimental data is shown in Figure 6 , which indicates that the predicted pressure is smaller than the measured data.

The friction in the pipe and heat transfer between the gas and solid walls were neglected in the SFLOW results shown in Figure 6 . Figure 7 shows the results with both friction and heat transfer effects being taken into account, which indicates that a better agreement with experimental data. This volume venting case has also been simulated using ISENTANK ${ }^{18}$, which assumes the flow in the path is isentropic. The SFLOW prediction in Figure 6 is very similar to the result from ISENTANK with a discharge coefficient of 1.0 while

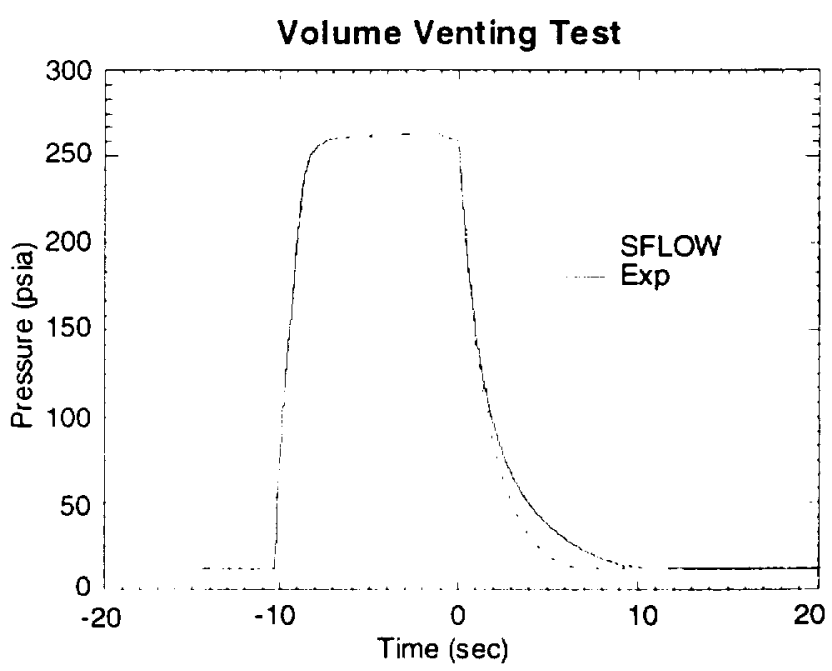

Figure 6. Comparison of the Predicted Pressure From SFLOW With the Experimental Data. (The Friction and Heat Transfer Were Neglected in the Prediction) 
that in Figure 7 is similar to that from ISENTANK with a discharge coefficient of 0.6

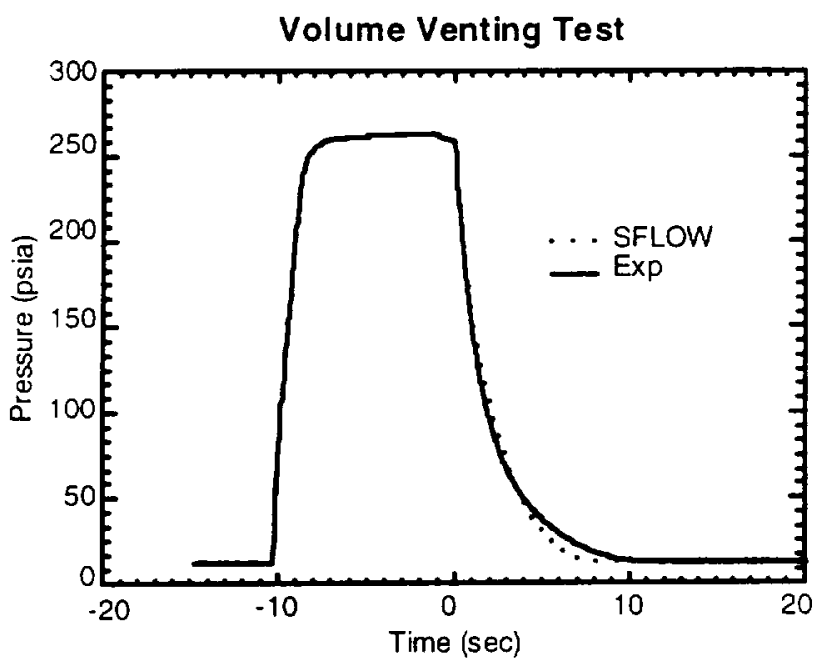

Figure 7. Comparison of the Predicted Pressure From SFLOW With the Experimental Data. (The Friction and Heat Transfer Were Accounted for in the Prediction)

\section{RSRM NOZZLE JOINT 4 TEST}

SFLOW was also used to simulate the RSRM nozzle joint 4 hot fire test ${ }^{16}$, which was also modeled by Clayton ${ }^{19}$. Figure 8 shows the location of joint 4 in the RSRM nozzle and the hot tlow test fixture. The insert is

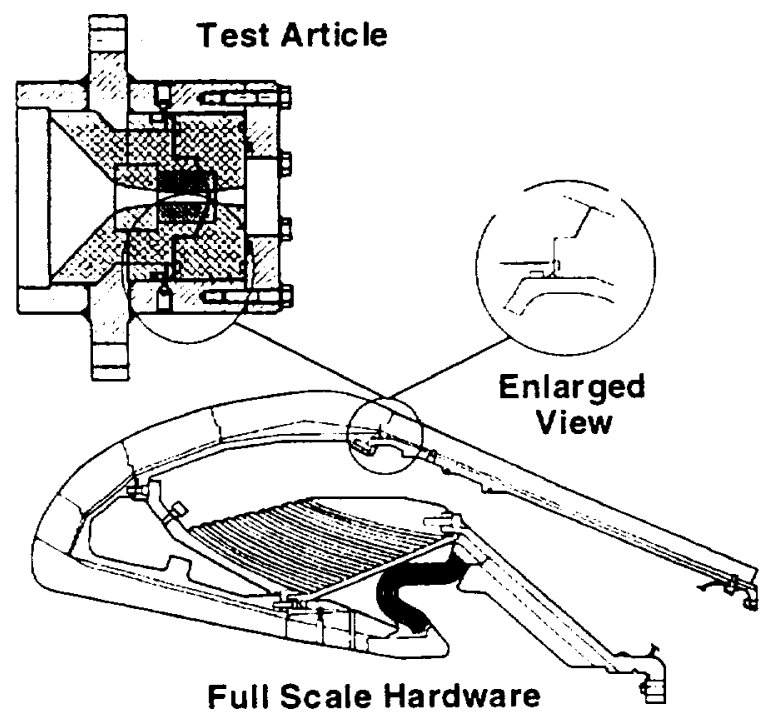

Figure 8. The RSRM Nozzle Joint 4 and Hot Flow Test Fixture the enlarged view of the joint 4. In this section, only comparisons of the SFLOW predictions with the measured data for configuration No. 8 at the 90 degree side will be discussed. The SFLOW results for other configurations, more results for this configuration, as well as the details of the model will be published later.

A schematic of the test fixture for the RSRM nozzle joint 4 hot flow test is shown in Figure 9. There are two fill-tubes and bottles connected to the primary O-ring gland, chamfer region, as well as the secondary O-ring gland. The SFLOW model consists of four volumes (the combustion chamber, primary O-ring gland, chamfer region, and secondary O-ring gland) and nine paths (one from the combustion chamber to the primary $\mathrm{O}$-ring gland, one from the primary O-ring gland to the chamfer region, one from the chamfer region to the secondary O-ring gland, two for the fill tubes and bottles connected to the primary O-ring, two for the fill tubes and bottles connected to the chamfer, two for the fill tubes and bottles connected to the secondary $O$ ring).

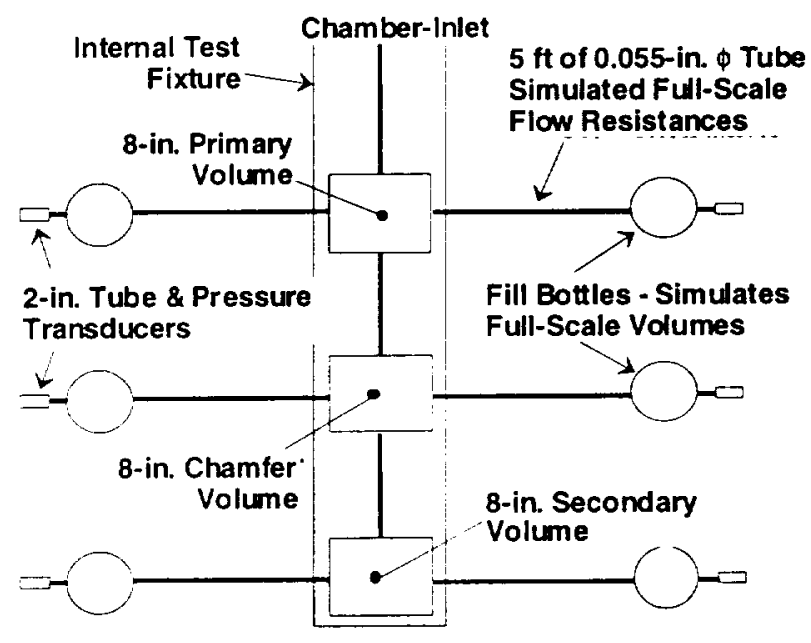

Figure 9. Schematic of the Test Fixture for the RSRM Nozle Joint 4 Hot Flow Test

Figure 10 shows the solid grid used for the RSRM nozzle joint 4 test with different colors for different materials. The pressure and temperature in the combustion chamber is specitied as input for the SFLOW prediction (see Figure 16 for the pressure, the temperature is $530^{\circ} \mathrm{R}$ initially and increases to $4900^{\circ} \mathrm{R}$ at $0.07 \mathrm{sec}$ and then remains at that high temperature). Impingement heat transfer is applied for several surfaces on the O-rings, the inlet path, and the chamfer region while minor losses are applied in the paths where the tlow turns. Steady-state gas-only CFD simulations such as those discussed in Laubacher et al. 
are used to determine which surfaces should have jel impingement heat transfer.

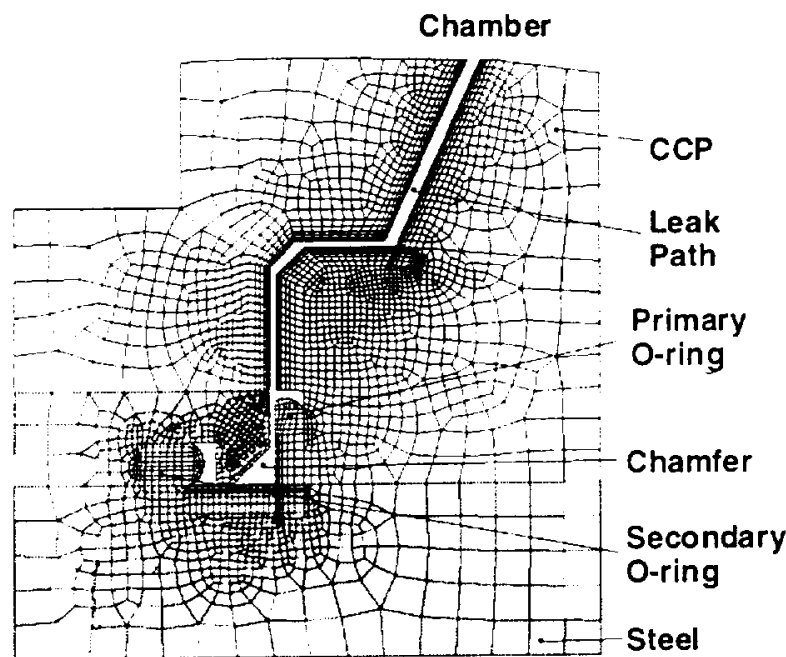

Figure 10. The SFLOW Grid of the Solid for RSRM Joint 4 Hot Test Simulation

Isocontours of the predicted temperatures of the solid at $4.0 \mathrm{sec}$ are shown in Figure 11 . Initially the temperature is at $530^{\circ} \mathrm{R}$. At $4.0 \mathrm{sec}$, the solid cells near the impinging surfaces as well as those near the flow path from the chanber to the primary O-ring are hot while the temperatures at the solid cells farther away are still very low.

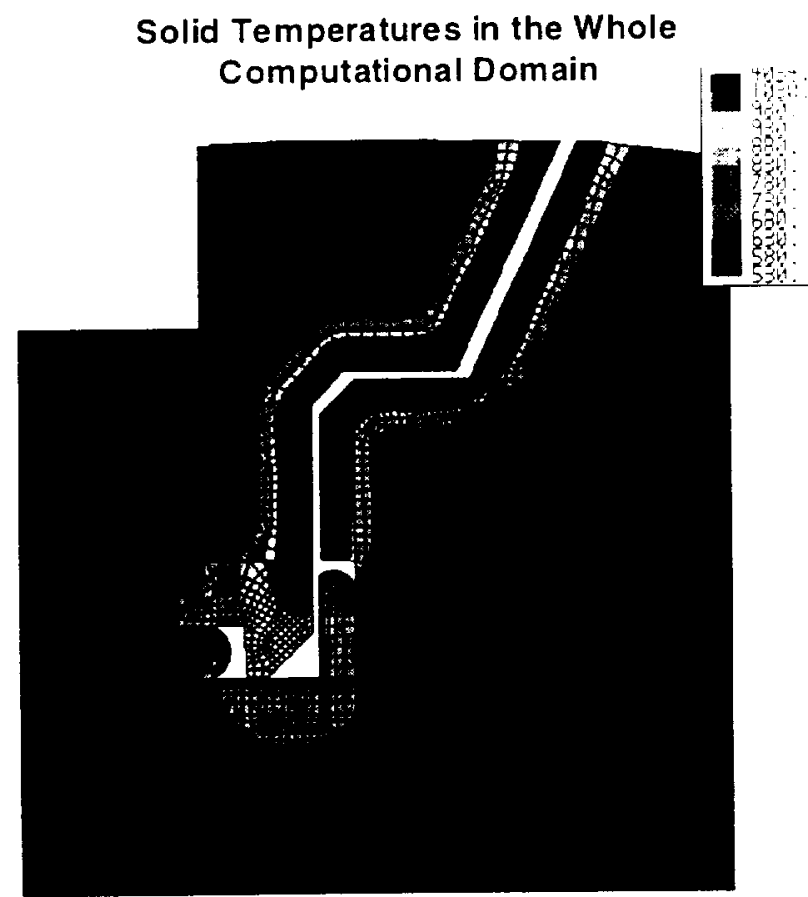

Figure 11. Isoconto urs of SFLOW Predicted Solid Temperatures at $4.0 \mathrm{sec}$

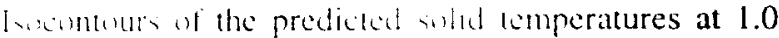

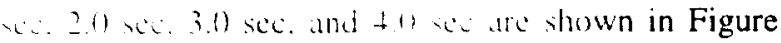
2. Figur: 13. Figure 14, and ligure 15, respectively, fil part of the domath moluding the O-rings and thamler. Si time increases. more solid heats up while the comperalures of the solid near the impingement surfices decrease due 10 heall conduction. Since the chermal conductivity is lareser for stecl than carbon

\section{Solid Temperatures in Part of the Computational Domain}

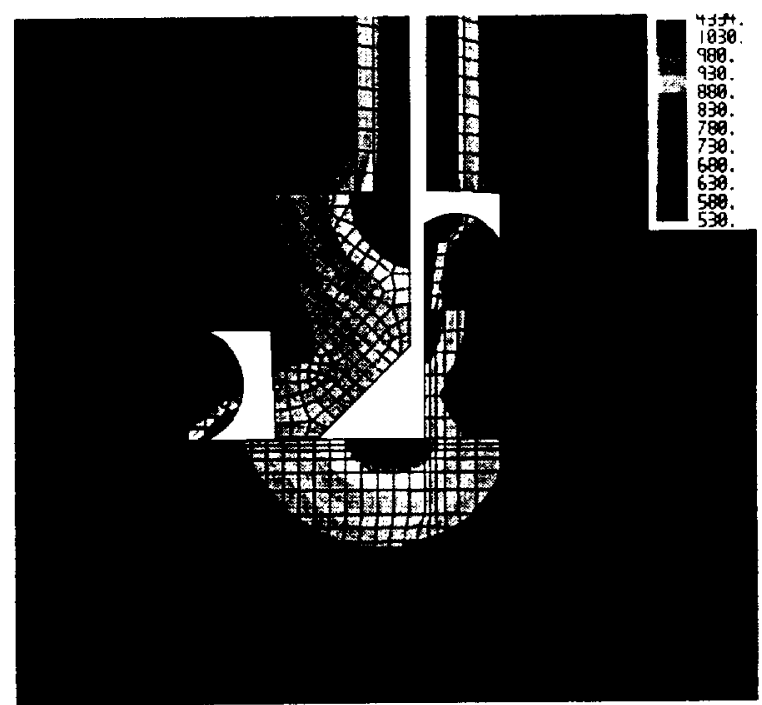

Figure 12. Isoconto urs of SFLOW Predicted Solid at $1.0 \mathrm{sec}$

\section{Solid Temperatures in Part of the} Computational Domain

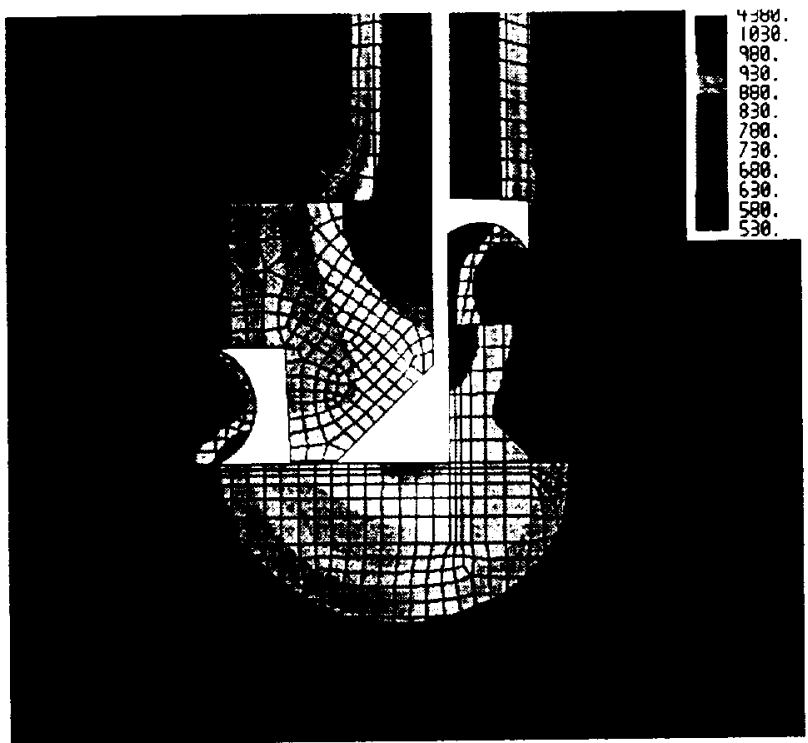

Figure 13. Isocontours of SFLOW Predicted Solid Temperatures at $2.0 \mathrm{sec}$

10 
Solid Temperatures in Part of the Computational Domain

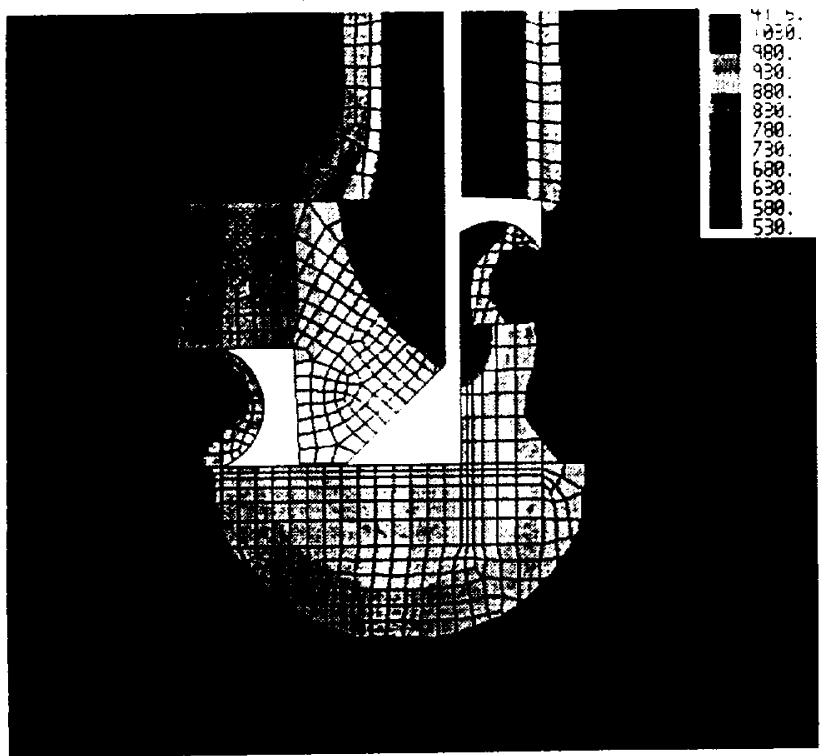

Figure 14. Isoconto urs of SFLOW Predicted Solid Temperatures at $3.0 \mathrm{sec}$

Solid Temperatures in Part of the Computational Domain

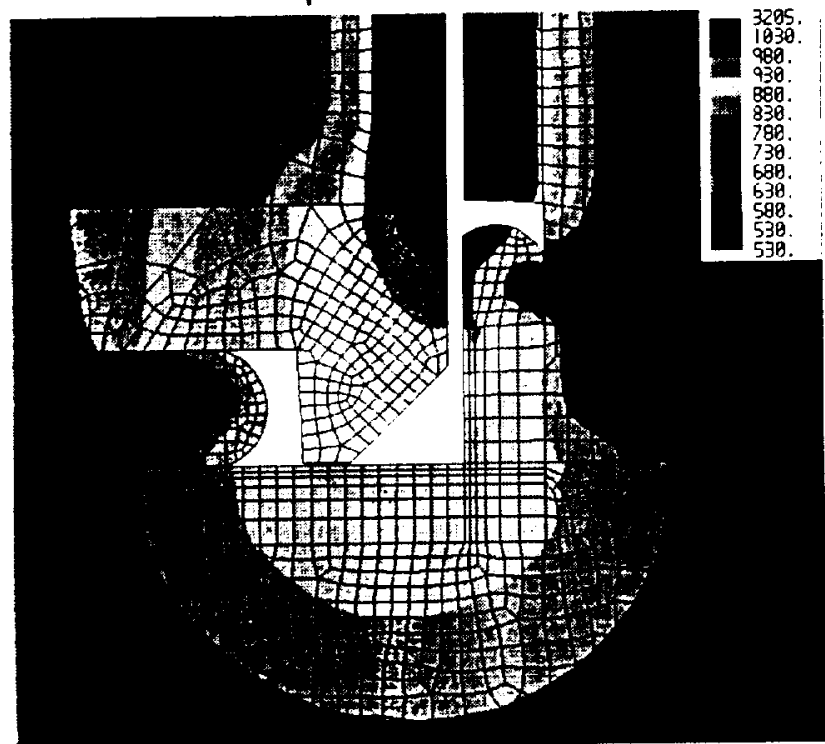

Figure 15. Isocontours of SFLOW Predicted Solid Temperatures at $4.0 \mathrm{sec}$

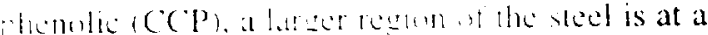

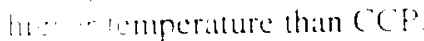

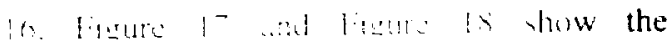

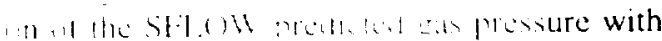

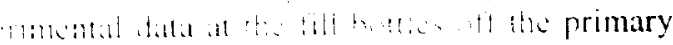

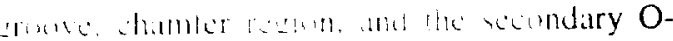

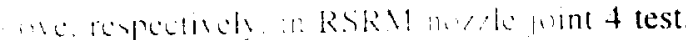
numn in lhese figlares a the pressure of the
Fill Bottle Pressure Off Primary O-ring Groove: RSRM Joint 4

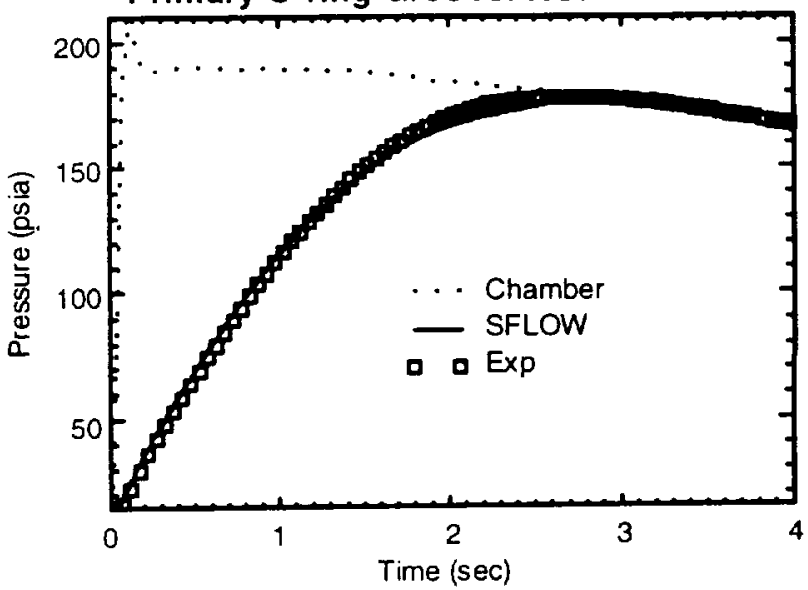

Figure 16. Comparison of the Predicted Gas Pressures With the Measured Data

Fill Bottle Pressure Off Chamfer Region: RSRM Joint 4

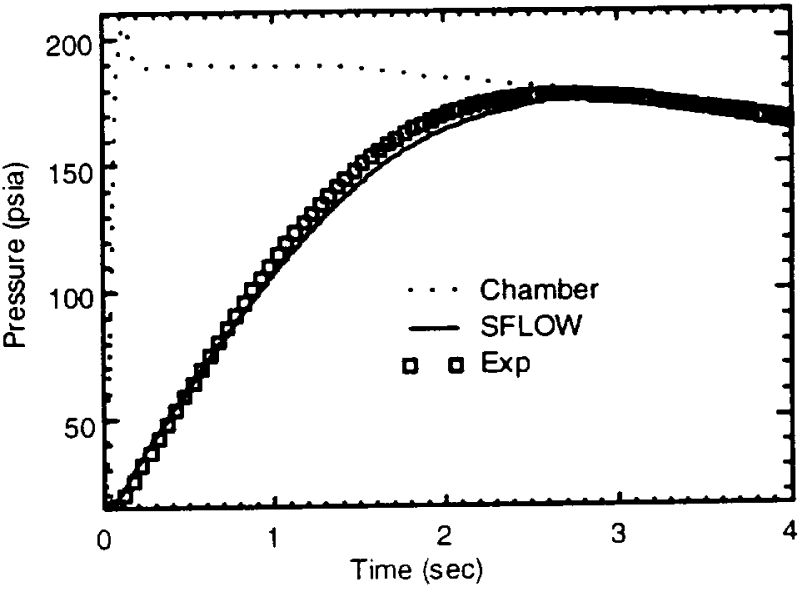

Figure 17. Comparison of the Predicted Gas Pressures With the Measured Data

Fill Bottle Pressure Off Secondary O-ring Groove: RSRM Joint 4

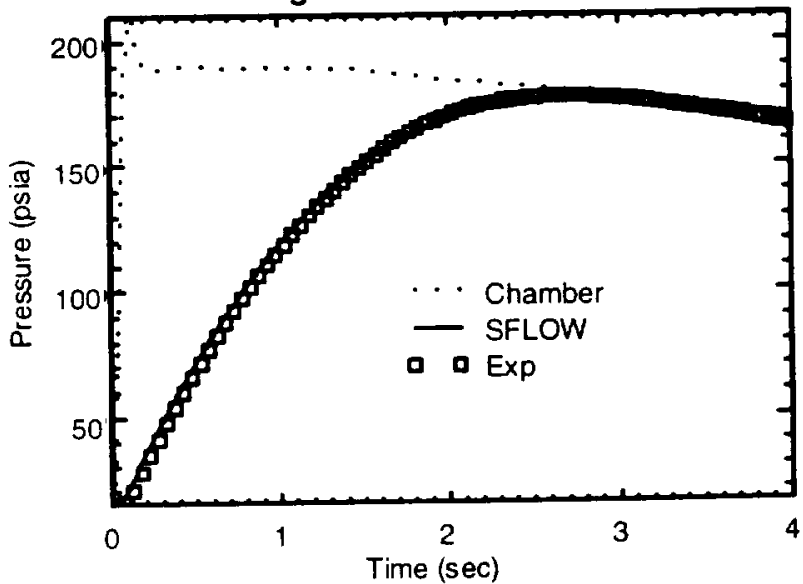

Figure 18. Comparison of the Predicted Gas Pressures With the Measured Data 
combustion chamber, which is an input to the SFLOW code. The pressures at all the fill bottles are very similar and the predicted values agree very well with the measured data.

The predicted temperatures of the fill bottles in the RSRM nozzle joint 4 test are compared with the measured data in Figure 19. The agreement is good considering that the chamber temperature is about $5,000^{\circ} \mathrm{R}$ while that in the fill bottles is less than $600^{\circ} \mathrm{R}$.

Fill Bottle Temperatures: RSRM Joint 4

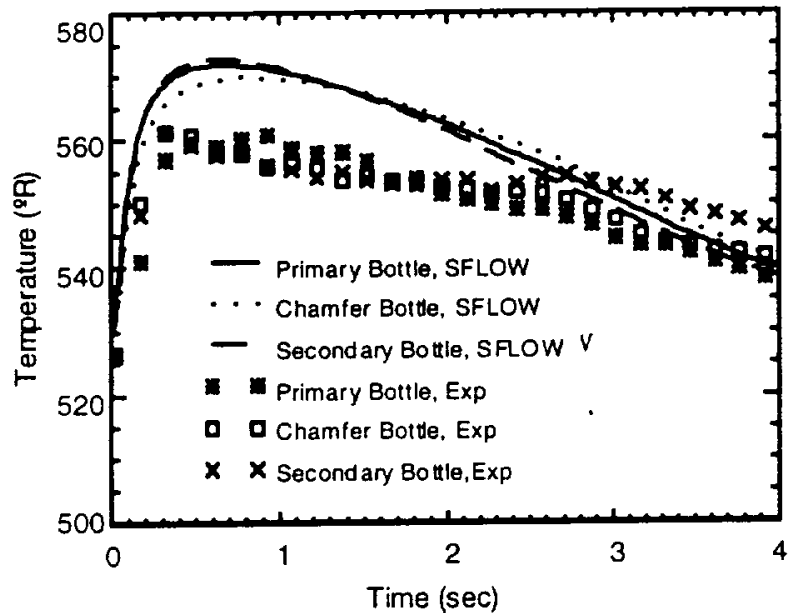

Figure 19. Comparison of the Predicted Gas Temperatures With the Measured Data

Figure 20 and Figure 21 show the predicted solid temperatures at two locations, one near the primary $\mathrm{O}$ ring (TI4 in Figure 22) and the other just before the secondary O-ring (T15 in Figure 22), together with the measured data at the same locations. As discussed by

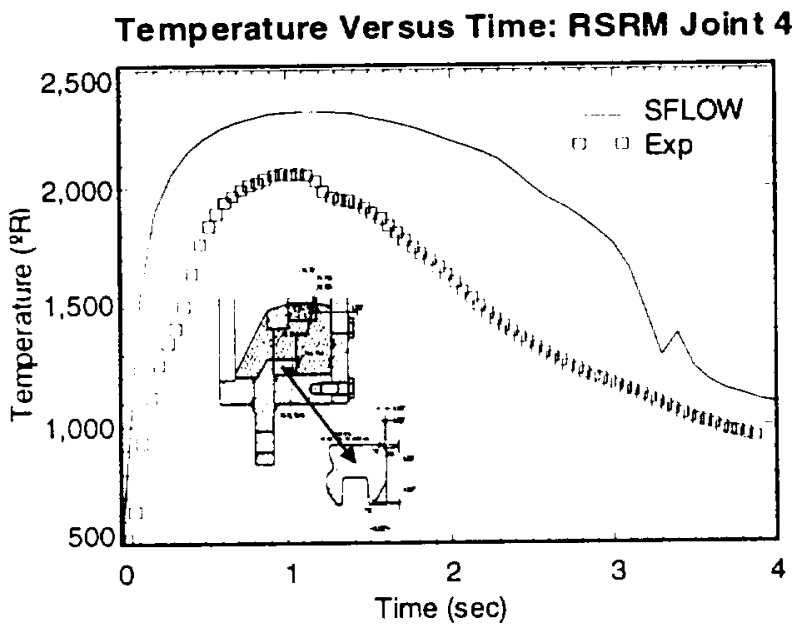

Figure 20. Comparison of the Predicted Temperature of the Solid Near the Primary Oring (T14 in Figure 22) With the Measured Data
Temperature Versus Time: RSRM Joint 4

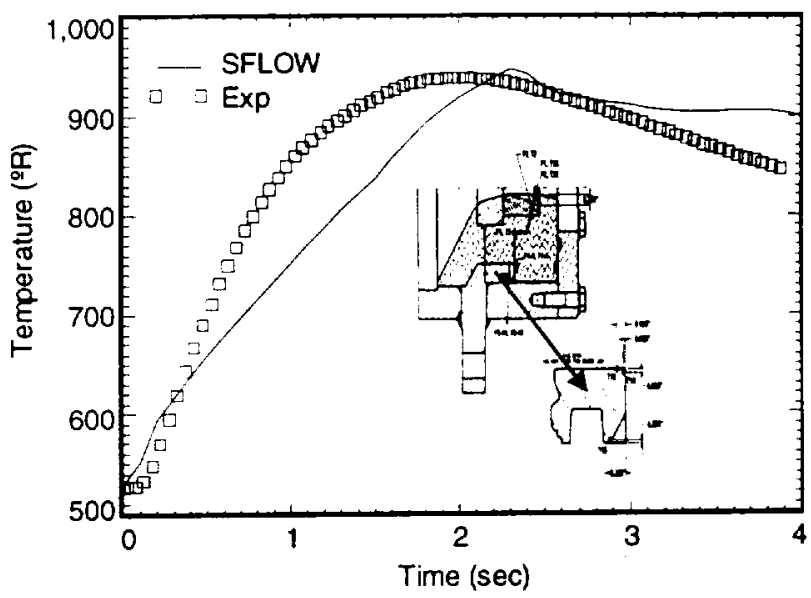

Figure 21. Comparison of the Predicted Temperature of the Solid Near the Secondary O-ring (T15 in Figure 22) With the Measured Data

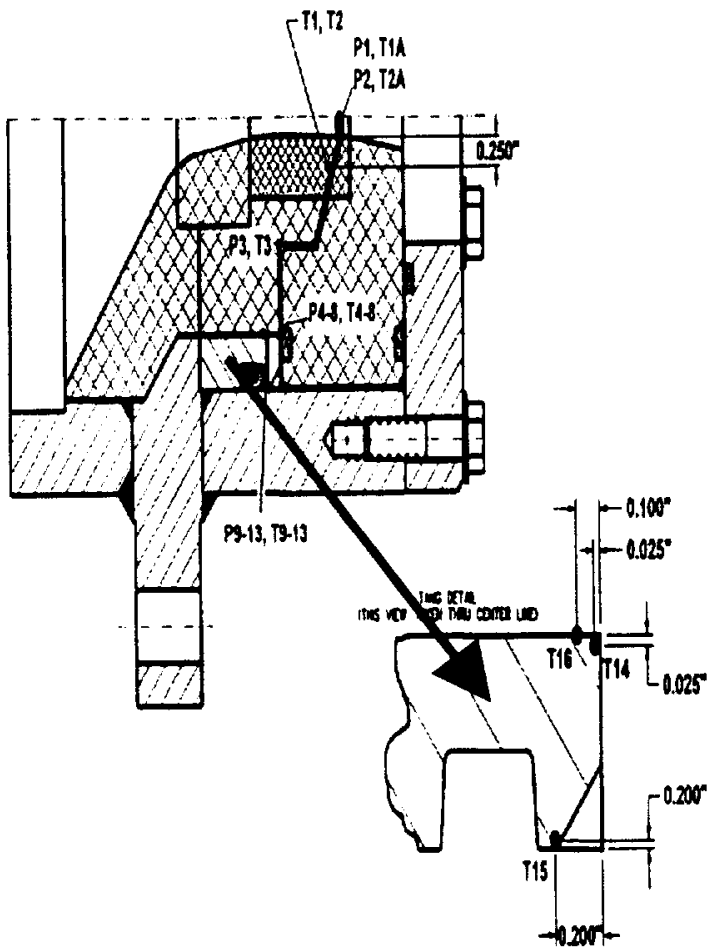

Figure 22. The Location of the Thermocouples in the RSRM Nozzle Joint 4 Test

Clayton "1", the measured temperatures are not very accurate due to the large gradients, tiny gaps and brief time scales. On the other hand, better agreement might be obtained by using a full three-dimensional solid grid. 
The predicted erosion of the secondary O-ring is shown in Figure 23. The predicted total erosion after $2 \mathrm{sec}$ is about $0.00813 \mathrm{in}$, which is very close to the measured value of 0.008 in. This agreement is excellent considering analytical modeling complexity and assumptions required, as well as the variability in measured data, measurement error due to very small dimensions and short time frame.

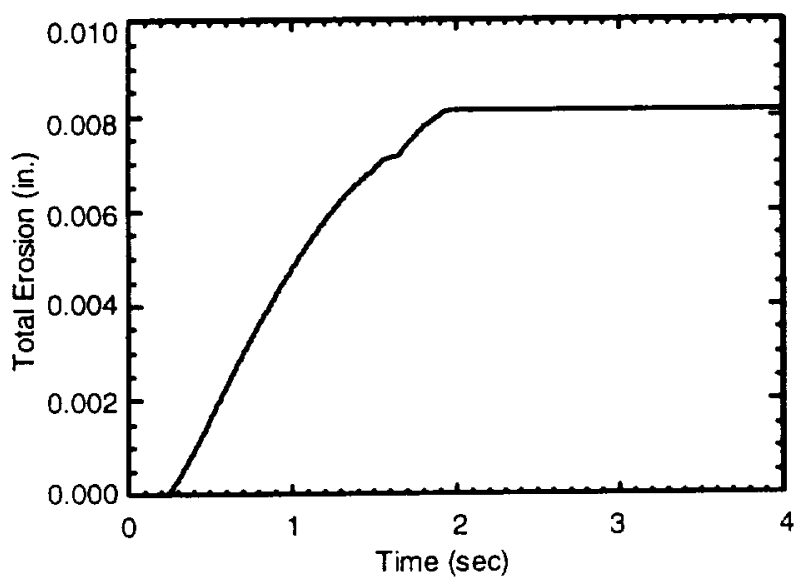

Figure 23. Secondary O-ring Erosion Predicted by SFLOW in RSRM Nozzle Joint 4 Test

As discussed above, most CFD applications in the RSRM joints do not include the solid region in the computational domain and the solid wall is assumed to be either adiabatic or isothermal. Figure 24 and Figure 25 compare the SFLOW predictions of the pressures and gas temperatures in the fill bottles with and without heat transfer between the gas and solid. It indicates that, without heat transfer, the fill time is reduced by a factor of about three and the gas temperature increases to more than $1,400^{\circ} \mathrm{R}$ from around $580^{\circ} \mathrm{R}$ with heat transfer. For these conditions, heat transfer to the solid wall is a significant driver for the problem.

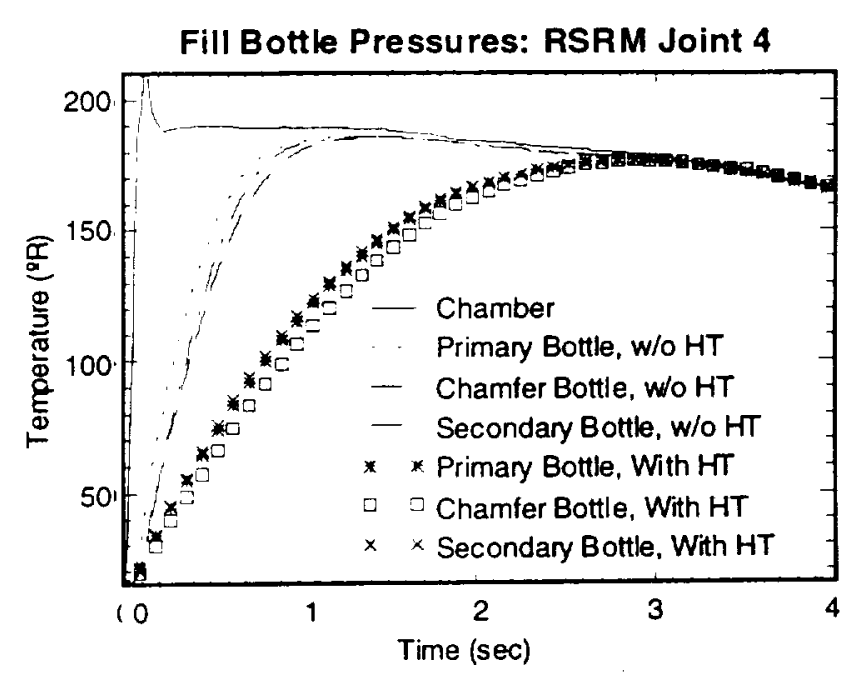

Figure 24. Comparison of the SFLOW Predicted Gas Press ure With and Without Heat Transfer

\section{Fill Bottle Temperatures: RSRM Joint 4}

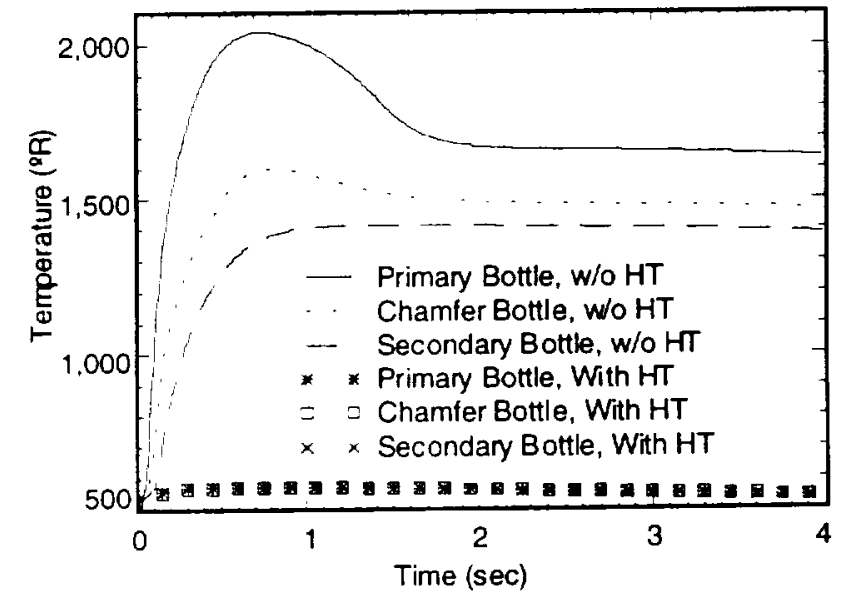

Figure 25. Comparison of the SFLOW Predicted Gas Temperature With and Without Heat Transfer 


\section{SUMMARY AND CONCLUSIONS}

A new thermal-flow simulation code, called SFLOW. has been developed to model the gas dynamics, heat transfer, as well as O-ring and flow path erosion inside the space shuttle solid rocket motor joints by combining SINDA/G ${ }^{\circledR}$, a commercial thermal analyzer. and SHARP ${ }^{\$}$, a general-purpose CFD code developed at Thiokol Propulsion. SHARP ${ }^{\circledR}$ was modified so that friction, heat transfer, mass addition, as well as minor losses in one-dimensional flow can be taken into account. The pressure, temperature and velocity of the combustion gas in the leak paths are calculated in SHARP ${ }^{\$}$ by solving the time-dependent Navier-Stokes equations while the heat conduction in the solid is modeled by SINDA ${ }^{\star}$. The two codes are coupled by the heat flux at the solid-gas interface.

A few test cases are presented and the results from SFLOW agree very well with the exact solutions or experimental data. These cases include Fanno flow where friction is important, Rayleigh flow where heat transfer between gas and solid is important, flow with mass addition due to the erosion of the solid wall, a transient volume venting process, as well as some transient one-dimensional flows with analytical solutions. In addition, SFLOW is applied to model the RSRM nozzle joint 4 subscale hot-flow tests and the predicted pressures, temperatures (both gas and solid). and O-ring erosions agree well with the experimental dati. It was also found that the heat transfer between gas and solid has a major effect on the pressures and temperatures of the fill bottles in the RSRM nozzle joint $\rightarrow$ configuration No. 8 test.

\section{REFERENCE}

1. Laubacher, B.A., Eaton, A.M., Pate, R.A., Wang. Q.. Mathias, E.C. and Shipley, J.L. 1999 "Coldflow simulation and CFD modeling of the space shuttle solid rocket motor nozzle joints," AIAA Paper 99-2793.

2. Eaton A. and Mathias, E. 2000 "Simulating heat transfer to a solid rocket motor nozzle-case-joint thermal barrier," AIAA Paper 2000-3807.

3. O'Malley, M.J. 1988 "A model for predicting RSRM joint volume pressurization, temperature transients, and ablation," AlAA Paper 88-3332.

4. O'Malley, M.J. 1987a "ORING2: volume filling and O-ring erosion prediction code with improved model descriptions and validation, Part I: Improved O-ring Erosion Prediction Code." Thiokol Corporation TWR-17030

5. OMalley, M.J. 1987b "ORING2: volume filling and O-ring erosion prediction code with improved model descriptions and validation, Part II: Improved volume filling model and code validation," Thiokol Corporation TWR-17031

6. O'Malley, M.J. 1990 "ORING2: volume filling and O-ring erosion prediction code with improved model descriptions and validation, Part III: User's guide." Thiokol Corporation TWR-50398

7. Clayton, J.L. 1995 "Joint pressurization routine (JPR) theoretical development and users manual," NASA-MSFC Internal Memorandum ED66 (95$01)$.

8. Network Analysis Inc. 1996 SINDA/G ${ }^{\otimes}$ User's Guide, Tempe, AZ.

9. Golafshani, M. and Loh, H.T. 1989 "Computation of two-phase viscous flow in solid rocket motors using a flux-split Eulerian-Lagrangian technique," AIAA Paper 89-2785.

10. Loh, H.T. and Golafshani, M. 1990 "Computation of viscous chemically reacting flows in hybrid rocket motors using an upwind LU-SSOR scheme," AIAA paper $90-1570$.

11. Loh, H.T., Smith-Kent, R., Perkins, F and Chwalowski, P. 1996 "Evaluation of aft skirt length effects on rocket motor base heat using computational fluid dynamics," AIAA paper 962645.

12. Wang, Q. 1999a "Theory Manual for SHARP": a general CFD solver," Thiokol Corporation TR11580

13. Wang, Q. 1999b "Programer's guide for SHARP": a general CFD solver," Thiokol Corporation TR11581

14. Wang, Q. 1999c "User's guide for SHARP": a general CFD solver," Thiokol Corporation TR11582

15. Cai, R. 1998 "Some explicit analytical solutions of unsteady compressible flow," Journal of Fluid Eng., Vol. 120, pp. 760-764.

16. Prince, A. 1999 "Final report for ETP-1385: Tortuous path thermal analysis test bed," Thiokol Corporation TWR-66623.

17. Idelchik, I.E. 1986 Handbook of Hydraulic Resistance, $2^{\text {nd }}$ Edition. Hemisphere Publishing Corp.

18. Wang, Q. 1998 "ISENTANK code," Thiokol Corporation MEMO 32B2-FY98-M029.

19. Clayton, J.L. 1999 "Reusable solid rocket motor nozzle joint-4 test correlated gas dynamics-thermal analysis," AIAA Paper 99-2791. 